\title{
The Impact of Human Resources Auditing on the Application of Governance in the Banking Sector in Jordan
}

\author{
Naila Medhat Al-Hameed \\ Dept. of Management, Amman Arab University-Jordan \\ E-mail: nailajoann2014@yahoo.com
}

Prof. Aktham A. Al-Sarayreh

Dept. of Management, Amman Arab University-Jordan

E-mail: sarah_aktham@yahoo.com

Dr. Samar S. Al-Tarawneh

Dept. of Management, Amman Arab University-Jordan

E-mail: samar_t72@yahoo.com

Received: January 25, 2017 Accepted: February 28, 2017 Published: April 11, 2017

doi:10.5296/ijhrs.v7i2.10949 URL: http://dx.doi.org/10.5296/ijhrs.v7i2.10949

\begin{abstract}
The purpose of this study was to investigate and measure the impact of Human Resources Auditing on the Application of Governance in the Banking Sector in Jordan, where the study population consisted of (26) banks operating in Jordan.

The study consisted of (250) people working at banks headquarters, and in auditing and human resources directorates, holding managers, chief section and employee positions.

Researcher suggested an action plan to carry out human auditing activities in accordance with auditing criteria and international governance principles and with Jordanian business environment as an attempt to clarify and highlight the mechanism of human resources auditing work and raise the awareness of this concept as well as to urge the start of its application effectively and basically within current auditing practices.

Results showed that human resources auditing has an effect on governance application in Jordanian banking sector, along with clear positive relationship and a healthy indicator
\end{abstract}


among requirements of human resources auditing and governance applications including the inclusion of human resources auditing as a principle requirement in the application of governance in Jordanian Banking Sector as well as to be contained Central Bank of Jordan laws and legislations

Keywords: Human Resources Auditing, Application of Governance, Banking Sector in Jordan.

\section{Introduction}

The concept of business ethics in organizations is connected with its resources and human energies where this concept is a beacon that lights the way for the organization and its components to walk confidently towards achieving its organizational goals, and creating a work environment characterized by transparency, accountability, disclosure and fairness under the umbrella of fixed professional ethics and principles.

From the term "ethics", the attention in the function of "human resources auditing" came as a part of the internal auditing system of business organizations, which are considered one of the most important tools of supervision and management that enable the organization to regulate and control the rhythm of the course of business as drawn and designed by the regulatory objectives sought to be achieved through directing its human energies and resources.

The modern departments consider "human resources auditing" as one of the tools of the administrative reform and development and correcting the defects of strategies and annual plans; it can be represented as the five senses of man since it is like the eye, ear, hand and tongue for the management seeking to achieve excellence, creativity and leadership to reach to the security station and continuity of development. The administration uses an important tool such as the process of " human resources auditing," to see and monitor performance, hear the views of the various parts of the administrative process, determine the error and correct it and enhance the effectiveness of the communication channels; modern departments are also able to sniff any danger or damage that may occur while implementing plans and strategies.

The growth and expansion of business organizations and their consequent separation from management led to the need for finding "rhythm controls" used by the business organizations in order to ensure the achievement of the objectives of the internal audit processes in general and the human resources auditing, in particular; they were represented in the growing interest of legislative and regulatory bodies and academic research for the concept of "governance", which created a wide framework composed of rules and principles that aim to control the decisions and jobs taken by the departments. Accordingly, they aimed at curbing corruption and abuse of power to guarantee the rights of stakeholders without discrimination or preference. These legislations commit organizations with certain levels of disclosure and transparency in making administrative and financial information assuring for the owners regarding the fact that their investments are governed by strict rules and regulations and ethical rules leading to their sense that their investments are "fine". 
The combination of the human resources auditing and the application of the principles and foundations of governance in organizations in general and in the banking sector in Jordan in particular is an important process that will represent one of the most important requirements of development in the Jordanian society, which is classified as one of the developing societies, which are in dire need of radical reform packages at all levels, whether they were : (political, economic, social, cultural or administrative); such packages work on changing the culture concepts found in the mechanisms of getting jobs like nepotism and creating new values and concepts such as fairness in recruitment, equal opportunity, fairness and transparency.

The function of human resources auditing will not bear fruits except when it is effective in doing tasks. However, the reality of many of the Jordanian business organizations and their suffering from the prevalence of the administrative corruption represented in nepotism and favoritism in jobs does not give any indication that this job is beneficial to organizations, which has necessitated doing such research in an attempt to collect and analyze data on the extent of the impact of practicing human resources auditing in the Jordanian business organizations -represented in the banking sector in Jordan, which is the research field in this study- on governance applications in this sector, analyze such data in a scientific and realistic method and propose appropriate solutions, which will activate the role of human resources auditing and improve its contribution in applying governance.

The Jordanian legislations represented in the legislations of the Central Bank of Jordan still lack the importance of the process of the "human resources auditing", but such process has become an important requirement for senior managements in the banking sector in Jordan; such departments realize the importance of the human element in creating a competitive advantage in the sector which is growing steadily, and the marketing and service competition increases day by day. The departments of the banking sector sees that "the human resources auditing," should be used as a regulatory tool for the performance of the human resources management in a way that ensures that the human resources do their tasks in line with the regulations, legislations, laws and regulations that control the relations at work which are organized by the Jordanian legislator in laws such as: the labor law, the law of social security and the laws of the occupational health in addition to the internal instructions and controls approved by the bank's management.

\section{Literature Review \& Study Hypotheses}

Through the preliminary survey carried out by the researcher, it is clear that there are banks in the Hashemite Kingdom of Jordan that do not pay the slightest attention for this important topic. There are no special sections for the human resources auditing and the researcher showed that some managers and employees are unaware of the concept of the human resources auditing and the corporate governance principles, and that some Jordanian banks suffer from problems in the understanding and applying these policies. The weak attention with the applications of governance and not activating them in the existing banking systems in Jordan sets off the alarm bells for the collapse of an important dynamic sector that would affect the whole national system; accordingly, the activation and application of corporate governance principles will absolutely lead to the development of the performance of the 
departments of this sector through its regulatory tools, which will balance trust and faith among the stakeholders who work on adding the expected returns to the national economy.

The business sector particularly the banking sector in Jordan does not mention its needs to ethical rules and regulations to ensure the proper performance of the business, increase the foundations of the trust of the stakeholders in the banking institution, and work to increase investors' appetite for dealing with the banking sector in Jordan in conjunction with the liberalization movements of the global financial markets represented in the movement of capital outside the borders of the mother country and the increasing size of companies and the separation of owners and departments, (Al-Agha, 2016, PP: 6-14).

The world is drawn towards the capitalist system by relying on the private sector organizations to achieve the desired economic growth, the banking sector in Jordan has an urgent need to create a legal framework that regulates the controls and the principles of the business ethics to restore balance to the process of governing funds and companies and support the supervision mechanisms weakened by the separation of ownership from the departments. The weakness of the control mechanisms is represented with the financial and administrative corruption, crises and collapses of major companies and global and local financial institutions. For these reasons and many others, a series of laws, regulations and ethical controls aim to achieve excellence and improvement for the quality of performance, as defined by the term "governance", whose various concepts and dimensions are clarified through a review of the views of administration thinkers in addition to the most important points of the legislations of the Central Bank of Jordan in the second part of this chapter.

How would be the case if the concept of (human resources auditing) was merged and adjusted according to the rhythm of (governance) in a sector considered as the lung of the Jordanian economy? The researcher may be able to answer this question through a literature review of these two concepts and through the results that have been reached which are based on collecting data from the study sample and analyzing it to prove the validity of this point of view.

The researcher defined the human resources auditing as a process of an organized evaluation through which the extent of evaluating the senior management of the human resources management is assessed; through it, a review is done for the philosophies, policies, procedures and operations of the organization with regard to the human capital management by examining and assessing all the activities of the human resources management and measuring the degree of the administrative compliance in the application of policies and procedures to detect the strengths and weaknesses in the methods of the human capital management and submit them in the form of reports for decision-makers in the organization. At the same time, the human resources auditing measure the extent of the ability of the human resources management to make an extra value from the human elements and improve 
the organization.

Although the attention with the human resources management is still an internal requirement coming through the senior management of the organization, it has not been mentioned by the Jordanian legislator represented in the Central Bank as an explicit legal requirement prompt for the banking sector of Jordan within the requirements of the items of the regulations of the corporate governance issued by the Central Bank of Jordan (the central bank, modified instructions of the corporate governance of banks 2016, pp. 3-34).

The ultimate goal of the existence of the concept of governance is the need for a feeling of security and safety. Yes, it is true. Any investor or shareholder wants to be assured that his money would be fine and that the company in which he served and invested works efficiently believing that the returns of his investments would be a reality that flourishes and progresses over time; he also wants to believe that the financial and administrative reports presented by the company are accurate and correct. Also, the whole society wants to ensure that the company continues to work on the development of the national economy, the employee wants to be reassured regarding the continuity of his work and that his income should not be concerned with and the shareholders also need to feel reassured by the performance of this company and that their rights are safeguarded and able to be received. Here comes the role of governance that represents the safety and confidence for those people and increases their confidence in the company and that their interests are fine; we can know their feelings without the presence of corporate governance since it is an adventure with undesirable consequences; it is a gamble and a bet on their future and living security.

The researcher believes that the governance as a concept did not come from a vacuum since it took off from the humanitarian principle of "conscience prevalence" through the activation of good and sound management; the concept expanded to include all the administrative, financial, economic, social and security aspects; governance has become a system through which the owners are controlled and the bank's management is directed to ensure the allocation of responsibilities, rights and duties among stakeholders and work on drawing policies and its operational procedures related to all the issues of the bank. Governance in the banking sector in Jordan represents the framework within which the strategic objectives are identified, mechanisms are examined and the performance of the executive management of the bank is controlled.

It could be argued that governance was to reduce the unacceptable actions of the executive departments, cover a variety of dimensions for the activities of the business management organization, whether administrative, financial, and legal to control the economic, moral and social human resources, and highlight the most important actions, decisions, management 
objectives, control and incentives to help achieve this; governance does not neglect the attention with all that matters stakeholders, owners, managers and boards of directors, and focus on the economic efficiency of the business organizations in their effective use of the financial and human resources and maintaining the sustainable competitive advantage through the application of the foundations and principles of governance.

The researchers reviewed a number studies that address the topics of this study, but separately, since the researchers found no studies that have linked the two variables together, as most of the studies relied on connecting a the variable of this with other topics.

Some previous studies (Froom, 2016) found that the deficiencies in the disclosure of financial information relating to the members of the boards of directors and the lack of responsibility and independence, which are considered the most important principles of corporate governance according to the Algerian law affecting negatively on the performance and competitiveness of these institutions.

Study of (Khadra,2015), worked on examining the reality of applying governance in small and medium enterprises in Algeria through a case study of NCI Robiah. The study found that the institutions should be eager to introduce flexibility and convenience factors and they should not imitate others when preparing the internal governance guide.

After reviewing the relevant literature, one key hypothesis was purposed:

Main Hypothesis H0: There is no statistically significant at the significance level $(\boldsymbol{\alpha}=\mathbf{0 . 0 5})$ for human resources auditing-with its dimensions (policies auditing, processes auditing, procedures auditing \& files and documents auditing) on the application of governance, with its dimensions (disclosure, responsibility, fairness \& independence) in the banking sector in Jordan. The following four sub-hypotheses were derived from the first main hypothesis:

H0-1: There is no statistically significant at the significance level $(\boldsymbol{\alpha}=\mathbf{0 . 0 5})$ for human resources auditing-with its dimensions (policies auditing, processes auditing, procedures auditing $\&$ files and documents auditing) on the disclosure in the banking sector in Jordan.

H0-2: There is no statistically significant at the significance level $(\boldsymbol{\alpha}=\mathbf{0 . 0 5})$ for human resources auditing-with its dimensions (policies auditing, processes auditing, procedures auditing \& files and documents auditing) on the responsibility in the banking sector in Jordan.

H0-3: There is no statistically significant at the significance level $(\boldsymbol{\alpha}=\mathbf{0 . 0 5})$ for human resources auditing-with its dimensions (policies auditing, processes auditing, procedures auditing \& files and documents auditing) on the fairness in the banking sector in Jordan. 


\section{Macrothink}

H0-4: There is no statistically significant at the significance level $(\boldsymbol{\alpha}=\mathbf{0 . 0 5})$ for human resources auditing-with its dimensions (policies auditing, processes auditing, procedures auditing \& files and documents auditing) on the independence in the banking sector in Jordan.

Figure (1) illustrates theoretical framework of the present study, proposed by the researcher, which comprises of human resources auditing (policies auditing, processes auditing, procedures auditing \& files and documents auditing) as independent construct and governance (disclosure, responsibility, fairness \& independence) as dependant constructs:

\begin{tabular}{|l|l|l|}
\hline Human Resources Auditing & \multicolumn{1}{c|}{ Governance } \\
- Policies Auditing & \\
- Processes Auditing & Disclosure \\
- Procedures Auditing & Files \& Documents \\
Auditing & Responsibility \\
- Fairness \\
- Independence
\end{tabular}

\section{Independent \\ Construct}

\section{Dependent Construct}

Figure 1. Theoretical Framework.

\section{Research Methodology}

This research is a quantitative study. A questionnaire was distributed to all banks headquarters in Jordan to collect data about investigated variables and test the study hypotheses.

\subsection{The banking sector in Jordan:}

The banking sector in Jordan consisting of twenty-six banks spread over thirteen Jordanian commercial banks, nine foreign banks listed on the Amman Stock Exchange, and four Islamic banks, three of which are Jordanian. The banking sector does not differ from other business sectors since it needs to be managed in accordance with a coherent framework consisting of 


\section{Macrothink}

rules and procedures that are suitable with its business; governance is the best framework with the ability to control the performance of this sector, ensure its success, convert resonant words like accountability, disclosure and transparency into reality that is positively reflected on the stakeholders and contribute to raising the overall development levels in the country.

\subsection{Unit of Analysis}

The researcher selected the banking sector to be the study population due to its great importance in the formation and development of the local Jordanian economy. The sampleintentional- consisted of workers in the head quarters of these banks in the department of audit and human resources, who occupy the following job titles: (director, head of the department, and employee). The number of the members of the study population was (834) persons who occupied the previously mentioned job titles. The sample represented $30 \%$ of the total study population by (250) persons. (Central Bank, Financial Stability Report 2015, p. 40); (the Association of Banks in Jordan 2015, pp. 41-71)

264 questionnaires were distributed to all the employees in the bank's head quarters, 250 valid questionnaires were analyzed which encompass (96.7\%) from all employees at banks head quarters.

\subsection{Research Tool}

A questionnaire was developed to measure the human resources auditing (policies auditing, processes auditing, procedures auditing \& files and documents auditing) as independent construct and governance (disclosure, responsibility, fairness \& independence) as dependant constructs. The questionnaire comprised of (78) items according to quintet Likert scale.

\subsection{Validity of Research Tool}

Questionnaire of the study was reviewed by professional in the field of human resources management and business administration to ensure that the items of the questionnaire can measure human resources auditing (policies auditing, processes auditing, procedures auditing $\&$ files and documents auditing) and governance (disclosure, responsibility, fairness \& independence) constructs.

\subsection{Reliability of Research Tool}


In order to verify the internal consistency of research variables, analysis of Cronbach alpha coefficient was used. Table (1) illustrates reliability coefficients of human resources auditing (policies auditing, processes auditing, procedures auditing \& files and documents auditing) as independent construct and governance (disclosure, responsibility, fairness \& independence) as dependant constructs that exceeded (70\%).

Table 1. Cronbach Alpha Coefficients

\begin{tabular}{|l|l|l|l|}
\hline $\begin{array}{l}\text { Independent Construct Variables } \\
\text { (Human Resources Auditing). }\end{array}$ & $\begin{array}{l}\text { Cronbach } \\
\text { Alpha }\end{array}$ & $\begin{array}{l}\text { Dependent Construct } \\
\text { Variables (Governance) }\end{array}$ & $\begin{array}{l}\text { Cronbach } \\
\text { Alpha }\end{array}$ \\
\hline Policies Auditing & 0.88 & Disclosure & 0.88 \\
\hline Processes Auditing & 0.75 & Responsibility & 0.81 \\
\hline Procedures auditing & 0.84 & Fairness & 0.84 \\
\hline Files\& Documents Auditing & 0.89 & Independence & 0.83 \\
\hline Reliability of Research Tool & $\mathbf{0 . 9 6}$ & & \\
\hline
\end{tabular}

\section{Research Findings}

Through this address, the researcher presented the results of the descriptive analysis of the independent and dependent variables of the study through analyzing the arithmetic means and standard deviations for the independent variables of the study, which is "the impact of the human resources auditing" along with the dependent variable of "governance" as shown in Table (2).

Table 2. Mean, Standard Deviation and Significance Level for the Impact of Human Resources Auditing on the Application of Governance in the Banking Sector in Jordan.

\begin{tabular}{|l|l|l|l|l|}
\hline No. & Item & Mean & S.D. & Sig. Level \\
\hline 1 & Policies Auditing & 3.85 & 0.523 & High \\
\hline 2 & Processes Auditing & 4.14 & 0.567 & High \\
\hline 3 & Procedures auditing & 3.79 & 0.557 & High \\
\hline 4 & Files\& Documents Auditing & 3.89 & 0.537 & High \\
\hline
\end{tabular}




\begin{tabular}{|l|l|l|l|l|}
\hline \multicolumn{2}{|c|}{ Total for Human Resources Auditing } & $\mathbf{3 . 9 2}$ & $\mathbf{0 . 5 4 6}$ & High \\
\hline 5 & Disclosure & 3.68 & 0.531 & High \\
\hline 6 & Responsibility & 3.79 & 0.532 & High \\
\hline 7 & Fairness & 3.73 & 0.560 & High \\
\hline 8 & Independence & 3.67 & 0.642 & High \\
\hline Total for Governance & $\mathbf{3 . 7 2}$ & $\mathbf{0 . 5 6 6}$ & High \\
\hline
\end{tabular}

Table (2) indicates that the values of the arithmetic means of the independent variable "human resources auditing" and its dimensions (policies auditing, processes auditing, auditing procedures and files and documents auditing and documents) had a high level, where the arithmetic means ranged (4.14 - 3.79) and the standard deviations of these dimensions were (0.567 - 0.523); all the fields of the independent variable of (1), (2), (3) and (4) had high levels of impact. This means that the overall result confirms the presence of a high level of impact of human resources auditing on applying governance, where the total arithmetic mean of the independent variable "human resources auditing" was (3.92) and a standard deviation of (0.546) with high levels.

Furthermore, the table indicates that the means of the dependent variable (governance) and its dimensions (disclosure, responsibility, fairness, and independence) had high levels, where the arithmetic means ranged between (3.79 - 3.68), while the standard deviations of these dimensions ranged between $(0.642-0.531)$, i.e., the presence of high levels of influence, as the overall proportion of the dependent variable (governance) had the arithmetic mean of (3.72) and a standard deviation of (0.566), which are high. This also means that the respondents of the sample members to the questions of the questionnaire were close to some extent taking a positive turn; the percent of the standard deviations indicates the scarcity of the sample answers on the arithmetic means according to the Five-Likert scale. That is, it indicates the presence of a statistically significant impact of the dimensions of human resources auditing on the dimensions of governance as is shown in the statistical tables that were later analyzed

4.1 Testing the Results of the Main Hypothesis

This hypothesis states that "there is no statistically significant impact at the level $(0.05=$ 


\section{Macrothink}

a) for the human resources auditing with its dimensions (policies auditing, processes auditing, auditing procedures and files and documents auditing) on the application of governance with its dimensions (disclosure, responsibility, fairness and independence) in the banking sector in Jordan."

To find out the impact of human resources auditing with its dimensions (policies auditing, processes auditing, auditing procedures and files and documents auditing) on the application of governance with its dimensions (disclosure, responsibility, fairness and independence) in the banking sector in Jordan, the multiple regression test was used through conducting the following pre-tests to ensure the validity of using the multiple regression model as follows:

\subsubsection{First: The Normal Distribution Test for the Study Variables (Normality)}

Depending on the Central Limit Theory of the normal distribution, the data follow the normal distribution because the number of data exceeds thirty. This is stipulated by the Central Limit Theory of the normal distribution, which states: "if the number of the members of the study sample is greater than 30, the data follow a normal distribution." (Abu Salih \& Awad, 1983, P.:142).

Table 3 The Normal Distribution Test for the Study Variables (Linear Correlation Coefficients)

\begin{tabular}{|l|l|l|l|}
\hline \multirow{4}{*}{ Variable } & \multirow{2}{|l|}{ Item } & \multicolumn{2}{|l|}{ Co-linearity } \\
\cline { 2 - 4 } & Tolerance & VIF \\
\cline { 2 - 4 } $\begin{array}{l}\text { Human } \\
\text { Resources } \\
\text { Auditing }\end{array}$ & Policies Auditing & 0.526 & 1.903 \\
\cline { 2 - 4 } & Processes Auditing & 0.546 & 1.831 \\
\cline { 2 - 4 } & Procedures auditing & 0.488 & 2.047 \\
\cline { 2 - 4 } & $\begin{array}{l}\text { Files\& Documents } \\
\text { Auditing }\end{array}$ & 0.663 & 1.509 \\
\hline
\end{tabular}

The above table no (3) represents the correlation impact scale among the independent variables on increasing the independent variable coefficient variable or the Variance Inflation Factor (VIF). As is shown in the table, the value of (VIF) of the model variables indicates that 


\section{Macrothink}

International Journal of Human Resource Studies

ISSN 2162-3058

2017, Vol. 7, No. 2

none of which was affected by the problem of multi-linear problem (Index Condition).

Furthermore, the above table shows the use of (Multi-co-linearity) to test the assumption of the lack of a high correlation among the independent variables. The researcher conducted the (VIF) test and the tolerance variance test for each variable in that the VIF should not exceed (10) and that the Tolerance is greater than (0.05). Most of them did not exceed this limit.

4.1.2 Second, the Results of the Multiple Regression \& One Way ANOVA Analysis

Table 4 Multiple Regression Analysis

\begin{tabular}{|c|c|c|c|c|c|c|c|}
\hline $\begin{array}{l}\text { Independent } \\
\text { Construct }\end{array}$ & $\mathbf{R}$ & $\mathbf{R}^{2}$ & $\mathbf{F}$ & Sig.*F & $\beta$ & $\mathbf{T}$ & Sig.*t \\
\hline Policies Auditing & \multirow{4}{*}{0.729} & \multirow{4}{*}{0.532} & \multirow{4}{*}{69.503} & \multirow{4}{*}{0.000} & 0.143 & 2.537 & 0.012 \\
\hline Processes Auditing & & & & & -0.028 & -0.550 & 0.583 \\
\hline Procedures auditing & & & & & 0.190 & 3.466 & 0.001 \\
\hline $\begin{array}{l}\text { Files\& Documents } \\
\text { Auditing }\end{array}$ & & & & & 0.463 & 9.459 & 0.000 \\
\hline
\end{tabular}

Table 5 One Way ANOVA Analysis

\begin{tabular}{|l|l|l|l|l|}
\hline $\begin{array}{l}\text { Independent } \\
\text { Construct }\end{array}$ & Total Squares & Freedom Degrees & Mean & Result \\
\hline Regression & 31.679 & 4 & 7.920 & $\begin{array}{l}\text { Rejection of the } \\
\text { null hypothesis }\end{array}$ \\
\cline { 1 - 3 } 0.114 Error & 27.917 & 245 & 0.114 & \\
\cline { 1 - 4 } Total & 59.596 & 249 & & \\
\hline
\end{tabular}

Given the previous tables no. ( $4 \& 5)$, there is a statistical impact of the human resources 
auditing with its dimensions of (auditing policies, processes auditing, auditing procedures and files and documents auditing) on the application of governance with its dimensions (disclosure, responsibility, fairness and independence) in the banking sector in Jordan. The results of the statistical analysis showed the presence of a statistically significant impact for the human resources auditing with its dimensions (policies auditing, processes auditing, auditing procedures and files and documents auditing) on the application of governance with its dimensions (disclosure, responsibility, fairness and independence) in the banking sector in Jordan, as the value of the correlation coefficient $(\mathrm{R})$ was $(0.729)$ at the level of significance $(\alpha \leq 0.05)$. As for the value of the coefficient $\left(R^{2}\right)$, it was $(0.532)$, which can be interpreted that the human resources auditing with its dimensions (policies auditing, processes auditing, auditing procedures and files and documents auditing) explains (53.20\%) of the changes in the application of governance with its dimensions ( disclosure, responsibility, fairness and independence) in the banking sector in Jordan, as the value of (F) was (69.503), which is statistically significant at $(\alpha \leq 0.05)$; this confirms the correctness of rejection of the null hypothesis, which stipulates: "there is no statistically significant impact at $(\alpha=0.05)$ for the human resources auditing with its dimensions of (auditing policies, processes auditing, auditing procedures and files and documents auditing) on the application of governance with its dimensions (disclosure, responsibility, fairness and independence) in the banking sector in Jordan. "

\section{Conclusions}

Through the above mentioned results, the researcher concluded:

\subsection{Theoretical conclusions}

1. The banking sector in Jordan lacks the existence of separate sections dealing with the human resources auditing.

2. The answers of the study sample concerning the human resources auditing were high with all its dimensions.

3. In response to the study sample, with respect to governance, all the dimensions of this variable had also high levels.

\subsection{Scientific Conclusions}

1. The banking sector in Jordan had high levels of recognizing the human resources auditing and corporate governance in spite of the fact that it lacks special sections for the human resources auditing. 
2. The banking sector in Jordan should pay more attention to employees in the auditing and human resources departments so they can be partners with the bank management in making policies and presenting their perspectives which promotes their loyalty and belonging to their work environment, and also increase their productivity as they feel the importance of being partners with the management in applying and implementing the work policies.

3. The banking sector in Jordan works within clear organizational structures in its authority and powers lines, the workers in this sector are keys for determining their functional goals and the banks' sector in Jordan is keen to smooth the flow of information between different functional levels within a single section and the bank as a whole despite its partial failure in the disclosure of the organizational structures and updating them on websites according to the requirements of the corporate governance guide issued by the Central Bank of Jordan.

4. It is noted that the banking sector in Jordan suffers from a partial lack of fair and firm procedures in applying the terms of the internal regulations set with regard to sanctions and rewards systems, for example; they had a medium level which means that the banking sector in Jordan should exert further efforts to apply these regulations and rules equally to ensure the satisfaction of employees and the integrity of the scales of applying such systems.

5. The banking sector in Jordan should reconsider the principle of disclosure, which is one of the most important pillars of governance that is framed within the laws and regulations of the Central Bank of Jordan; it was noted by the results that the majority of the items of disclosure had medium statistical percentages though the total index value was high. This means that there is a relative deficiency in the application of the administrative disclosure requirements in this sector.

6. The banking sector in Jordan should take care of applying the indices of responsibility and fairness, one of the pillars of governance, and apply the concept of the application of laws on all workers in the bank with the same pattern, and the fact that there is no one except the senior management that is above the rules, regulations and laws to ensure fair and healthy environment, where the employees feel at ease and satisfaction and more belonging to their jobs and places of work.

\section{Recommendations}

Here, the researcher presented the most important recommendations reached by the results of this study as well as some suggestions that could explain the important findings and recommendations of the study.

1. Supporting the scientific research in terms of the human resources auditing, looking at the experiences of countries applying this harmonious concept, applying the corporate governance in the banking sector in these countries, and saving time, effort and advantages along with all that can be earned by the banking sector in Jordan in auditing the human resources as well as the principles of effective governance; this has innumerable benefits in 
avoiding human capital management risks inherent in saving time, effort and investment mistakes in facing errors and trying to solve them or leave them as is- i.e. benefitting from the experiences of these countries and applying their experiences to commensurate with the requirements of the management of the banking sector in Jordan.

2. The researcher hopes for the continuity of the awareness of the importance of human resources since the banking sector in Jordan is considered a real capital and a resource, investment and a great competitive advantage.

3. The researcher hopes from the banking sector in Jordan to spread the culture of human resources auditing and the application of corporate governance as one of the strategic success tools, create the sustainable competitive advantage through the human resource in the banking sector in Jordan for those interested in this sector through seminars, courses and publications of the organization for the correct application of the mechanisms for the implementation of the human resources auditing under the umbrella of governance, and establish special sections for the human resources auditing that work consistently with the internal audit departments, corporate governance and compliance.

4. The researcher hopes that the banking sector in Jordan pay attention to the human resources auditing, and the independence of the audit process being a process that affects the application of governance by providing the appropriate environment that is far from the relations that may remove objectivity from the audit process and those working on it. Accordingly, the banking sector in Jordan should find clear and decisive mechanisms to avoid conflicts' clash, find an ethical working environment, improve the general ethical conventions of staff specially for the employees of the Auditing Department, spread the culture of awareness and pay interest in applying the code of ethics in all transparency and objectivity to ensure that workers in the auditing departments master any dominance by other parties.

5. The researcher hopes for the continuity of the banking sector in Jordan by the principle of disclosure through undertaking the process of disclosure in the right time without any delay or justification for the failure in the disclose operations because this indicator has a great importance in confirming the effectiveness of the human resources auditing and increasing the rates of trust of those interested in the bank.

6. The researcher hopes for the continuity of the banking sector in Jordan in commitment with the laws, regulations and legislations, which would affect the application of corporate governance through its constant work to improve and strengthen its domestic laws and legislations in harmony with the laws and legislations set.

7. The banking sector in Jordan should strive to avoid the severe impacts and consequences that may occur as a result of the disruption of the application of governance criteria by enhancing the principles of disclosure, responsibility, independence, and fairness and granting each party of the governance formula full independence to ensure doing the tasks assigned to them flawlessly.

8. The researcher hopes that the banking sector in Jordan continue all its updates and amendments relating to corporate governance that are issued by the Central Bank of Jordan 
and the global institutions and activating them in the governance guides related to each bank.

9. The researcher hopes from the banking sector in Jordan to take into account the results of the auditing and disclosure reports and work on correcting the flaws that emerged from these reports.

10. The researcher hopes from the staff in the Auditing Department in the banking sector in Jordan to deepen the different aspects of governance and the full understanding of its mechanisms of application being a healthy indicator for the success of the objectives of the human resources auditing and due to the different difficulties and risks faced by the auditor as a result of the sensitivity of the job carried out.

11. The researcher recommends conducting further field studies dealing with the concept of human resources auditing in different sectors of business except for the banking sector where the Arabic studies available in the Arabic library discusses the theoretical framework of this concept only.

12. The researcher hopes from the decision-makers in Jordan to add the requirement of the human resources auditing as an administrative and legal requirement through the managements of the banking sector in Jordan and framing them within the corporate governance law by the Central Bank of Jordan.

13. Paying maximum attention of the annual reports issued by the banking sector in Jordan and measuring the degree of disclosure and transparency in it.

14. Paying attention to the international criteria of auditing the human resources and working on applying them in the banking sector in Jordan in a consistent method with the governance applications and the internal regulations of the Jordanian banks.

15. Paying attention to the staff of the Auditing departments and train them through giving them modern knowledge and skills that help them develop their performance and knowledge under the framework of human resources auditing to support the application of corporate governance in the banking sector in Jordan.

16. The researcher hopes that the banking sector in Jordan, which works on developing the application of the concept of human resources auditing on the work plan and the organizational structure to manage the human resources auditing-hopes for - paying the required attention that it might be the first building block in the establishment of scientific, professional and legal rules for the concept of human resources auditing.

\section{Acknowledgement}

The research is sub. Thanks for Prof. Aktham Al-Sarayreh, Amman Arab University.

\section{References}

Ibrahim, Irshid and Zaher, Attah, (2014). The Impact of the Bank's Internal Governance Structure on its Performance - An Applied Study of a Sample of Jordanian Commercial 
Banks Listed on the Amman Stock Exchange, research presented in the fifth scientific conference in the Republic of Iraq, Baghdad College of Economic Sciences, University, Baghdad.

Al-Imam Omar and Al-Tahir, Ali, (2013). Towards a Theoretical Framework to Audit the Human Resources, the Journal of Economic Sciences, Vol. 14, No. 1, pp. 111-133.

Balbaa, Muhammad, (2016). Corporate Governance and its Role in Facing the Administrative and Financial Imbalances, the Arab Organization for Administrative Development publications, League of Arab States, Cairo.

Albulada et al. (2012). Risk Management in Light of the Pillars of Institutional Control, a Field Study in the Jordanian Arab Bank, Al-Mansour Journal, Vol. 2, No. 18, pp. 102-205.

Al-Barghouti, Samir (2007). A Study on the Role of the Internal Auditor in the Risk Management in the Jordanian Commercial Banks, Zitouna University, Jordan.

Arab Bank, (2016). Corporate Governance Guide, No. 63/2016, Amman, Jordan.

Central Bank of Jordan (2016). Revised Regulations of the Corporate Governance of Banks, Amman, the Ministry of Finance.

Central Bank of Jordan (2015). Financial Stability Report, p. 4, Amman, the Ministry of Finance.

Juma'a, Hilmi, (2015). The Ethics of the Accounting Profession and Institutional Control, Vol. 1, Amman, Al-Safa'a House of Publishing and Distribution.

Association of Banks in Jordan (2015). Annual Report, number (37), Amman, Jordan.

Arab Society of Certified Accountants, (2014). Annual Report, p. 8, Amman.

Al-Jawhar, Karima, Al-Ogda, Saleh (2007). A Study in the Re-engineering of Internal Auditing in the Light of the International Criteria and their Impact on Enhancing Risk Management, Journal of the University of Applied Sciences, University of Applied Sciences, Jordan.

Al-Khuzami, Abd Al-Hakim Ahmad, (2003). Human Resources Management. Where to? Challenges, Experiences, and Aspirations, Cairo, International books house of publishing.

Khadra, Sadiqi (2015). The Reality of the Application of Governance in Small and Medium-Sized Institutions- A Case Study in NCI, Rubieh, Algeria, PHD Thesis, unpublished, Abu Bakr Belcaid University, Tilmesan, Algeria.

Abd Al-Mune'imoneim, Osama, and Al-Ajlouni, Ahmad, (2013). Sustainability Reports: True Embodiment of Institutional Governance in Companies- Field Study from the Perspective of Jordanian External Auditors, Journal of Anbar University for Economic and Administrative Sciences, Vol. 5, No. 10, pp. 153-180.

Al-Qarni, Bin Abd Al-Qadir Ahmad, (2014). Obstacles to Discover the Social 


\section{Macrothink \\ International Journal of Human Resource Studies \\ ISSN 2162-3058 2017, Vol. 7, No. 2}

Responsibility of the Business Organizations in Saudi Arabia, (the Views of the External Auditors and Companies), Jordan Journal of Business Management, Vol. 10, No. 3, pp. 70-298.

Mohammed, Amal (2005). Internal Audit's Role in Supporting the Effectiveness of Corporate Governance, Journal of Business Studies and Research, Volume 1, Issue 2, Banha University, Egypt, pp. 117-330.

Mattar, Mohammad, and Nour, Abd Al-Nasser, (2007). Extent of the Commitment of the Jordanian Public Shareholding Companies to the Principles of Corporate Governance, (a Comparative Analysis between the Banking and Industrial Sectors), Jordan Journal of Business Management, Vol. 3, No. 1, pp. 39-109.

Howari, Miraj (2010). (Accepted for Publication). Corporate Governance in the Banking and Financial Sector and its Role in Establishing the Rules of Transparency, AlAghawat University Publications, Algeria.

\section{Copyright Disclaimer}

Copyright for this article is retained by the author(s), with first publication rights granted to the journal.

This is an open-access article distributed under the terms and conditions of the Creative Commons Attribution license (http://creativecommons.org/licenses/by/3.0/). 